\title{
Ribavirin Protects Syrian Hamsters against Lethal Hantavirus Pulmonary Syndrome - After Intranasal Exposure to Andes Virus
}

\author{
Monica Ogg ${ }^{1}$, Colleen B. Jonsson ${ }^{2}{ }^{*}$, Jeremy V. Camp ${ }^{2}$ and Jay W. Hooper ${ }^{1}{ }^{*}$
}

1 Molecular Virology Branch, United States Army Medical Research Institute of Infectious Diseases, Fort Detrick, MD 21772, USA; E-Mail: Monica.m.ogg.ctr@mail.mil

2 Department of Microbiology and Immunology, Center for Predictive Medicine for Infectious Diseases and Biodefense, Louisville, KY 40202, USA; E-Mail: jvcamp01 @exchange.louisville.edu

* Authors to whom correspondence should be addressed; E-Mails: cbjons01 @ louisville.edu (C.B.J.); jay.w.hooper@us.army.mil (J.W.H.); Tel.: +1-502-413-1177 (C.B.J); +1-301-619-6101 (J.W.H).

Received: 5 September 2013; in revised form: 23 October 2013 / Accepted: 31 October 2013 / Published: 8 November 2013

\begin{abstract}
Andes virus, ANDV, harbored by wild rodents, causes the highly lethal hantavirus pulmonary syndrome (HPS) upon transmission to humans resulting in death in $30 \%$ to $50 \%$ of the cases. As there is no treatment for this disease, we systematically tested the efficacy of ribavirin in vitro and in an animal model. In vitro assays confirmed antiviral activity and determined that the most effective doses were $40 \mu \mathrm{g} / \mathrm{mL}$ and above. We tested three different concentrations of ribavirin for their capability to prevent HPS in the ANDV hamster model following an intranasal challenge. While the highest level of ribavirin (200 mg/kg) was toxic to the hamster, both the middle $(100 \mathrm{mg} / \mathrm{kg}$ ) and the lowest concentration $(50 \mathrm{mg} / \mathrm{kg}$ ) prevented HPS in hamsters without toxicity. Specifically, 8 of 8 hamsters survived intranasal challenge for both of those groups whereas 7 of 8 PBS control-treated animals developed lethal HPS. Further, we report that administration of ribavirin at $50 \mathrm{mg} / \mathrm{kg} /$ day starting on days $6,8,10$, or 12 post-infection resulted in significant protection against HPS in all groups. Administration of ribavirin at 14 days post-infection also provided a significant level of protection against lethal HPS. These data provide in vivo evidence supporting the potential use of ribavirin as a post-exposure treatment to prevent HPS after exposure by the respiratory route.
\end{abstract}

Keywords: hantaviruses; ribavirin; hamster; prophylactic; post-exposure antiviral 


\section{Introduction}

Hantaviruses are enzootic viruses of rodents which cause two severe vascular-leak diseases in humans [1], hemorrhagic fever virus with renal syndrome (HFRS) and hantavirus pulmonary syndrome (HPS). The Old World hantaviruses, which cause HFRS, are harbored by various Murinae and Arvicolinae rodent species throughout Europe and Asia [2,3]. The second disease, HPS, is caused by New World hantaviruses harbored by Sigmodontinae and Neotominae rodent species within the Americas. Infections of humans by hantaviruses presumably occur by inhalation of rodent excreta [4,5]. Old (HFRS-causing) and New World (HPS-causing) viruses have a global public health impact estimated at over 100,000 cases each year with lethality ranging from $1 \%$ to 50\% [1]. In the Americas, HPS affects approximately 300 people a year with a mortality rate of between $15 \%-50 \%$. There are no FDA-approved vaccines or therapeutic interventions for the prevention or treatment of either HFRS or HPS.

In human disease, HPS manifests itself in massive pulmonary edema followed by shock and cardiac dysfunction [1,6]. In contrast to other HPS-causing hantaviruses, persuasive evidence suggests person to person dissemination of Andes virus (ANDV) in endemic regions of Chile and Argentina [7-13]. The Syrian hamster-ANDV model of HPS closely resembles the human disease both in time course and in disease manifestation [14-17]. Similarities include incubation time, rapid disease onset, infected endothelial cells, pulmonary edema, pleural effusion, and shock. ANDV is lethal in hamster when administered by parenteral (i.e., subcutaneous, intramuscular, or intraperitoneal) or mucosal routes (i.e., intranasal, intragastric) $[15,18,19]$. This model has been used to test candidate countermeasures, such as immune serum, with success [20-23].

The discovery of new antiviral compounds to prevent hantaviral infection has been limited. Ribavirin (1- $\beta$-D-ribofuranosyl-1,2,4-triazole-3-carboxamide) is effective at inhibiting virus replication of HPS and HFRS viruses. Ribavirin is a nucleoside analogue of guanosine. The mechanism of action has been difficult to elucidate because of its ability to interact not only with host cell targets, but also with viral targets. For example, it has been shown that ribavirin can inhibit host-cell inosine monophosphate dehydrogenase as well as Hantaan virus (HTNV) polymerase activity [24], which in turn can increase mutational frequency [25-27]. In vitro, ribavirin has a 50\% effective concentration $\left(\mathrm{EC}_{50}\right)$ value ranging from 1-15 $\mu \mathrm{g} / \mathrm{mL}$ when tested in Vero E6 cells with HTNV, ANDV, Sin Nombre virus (SNV), or Maporal virus (MPRLV) [18,28-30].

In the lethal, suckling mouse model of HFRS with HTNV, ribavirin can prevent mortality when treatment is begun as late as 6 days post-infection [31]. In the infection, suckling mice model with Seoul virus, ribavirin limits virus replication at $25 \mathrm{mg} / \mathrm{kg}$ and $50 \mathrm{mg} / \mathrm{kg}$ resulting in $68 \%-81 \%$ survival [32,33]. There has been limited research using small animal models of HPS-causing hantaviruses. The deer mouse model of persistent SNV infection shows that ribavirin was effective at inhibiting infection when given at $100 \mathrm{mg} / \mathrm{kg}$ in a dose-dependent manner when administered one hour before virus infection [29]. While promising, the deer mouse is a natural rodent reservoir for SNV infection, and does not show any signs of disease. More recently, Safronetz et al. showed that treatment with ribavirin up to three days after intraperitoneal challenge with ANDV protected hamsters from lethal HPS [18].

Antiviral compound derivatives based upon the structure of ribavirin have shown success at limiting hantaviral replication, for both HFRS and HPS associated hantaviruses, in vitro and in vivo with lower 
apparent toxicity [34,35]. Additionally, Favipiravir (T-705, 6-fluoro-3-hydroxy-2-pyrazinecarboxamide), a new broad-spectrum antiviral [36,37], shows an $\mathrm{EC}_{50}$ values of $65-93 \mu \mathrm{M}(16-23 \mu \mathrm{g} / \mathrm{mL})$ against MPRLV, ANDV, SNV and two Old World viruses, Dobrava and Puumala viruses, when tested in vitro [30]. T-705 has broad spectrum antiviral activity against other members of the Bunyaviridae family [38]. In vivo efficacy of T-705 has been reported in the lethal hamster model of ANDV [37].

Clinical trials in China and Korea have shown efficacy in treatment with ribavirin for patients diagnosed with HFRS [39,40]. However, a recent investigation shows that treatment needs to begin before the oliguric phase to prevent mortality [41]. In these clinical studies using intravenous ribavirin treatment of HFRS, human cases caused by HTNV show improvement with a decrease in occurrence of oliguria and severity of renal insufficiency [41]. Human trials using ribavirin for treatment of HPS have been attempted. Unfortunately, due to a limited number of participants the trials have proved inconclusive due to lack of statistical power [42]. Another difficulty with human trials is the fact that most of the study participants were not enrolled in the study until they were already in the cardiopulmonary phase of the disease which usually results in rapid failure and death. This prevents an accurate assessment of the treatment protocol [43,44]. With what little data has been collected the results imply that ribavirin has no effect on disease course outcome. However, no studies have been performed where the patients were in the incubation phase or just prior to cardiopulmonary phase thus allowing treatment protocols the necessary time to prove efficacy.

Here we tested whether ribavirin could be used post-exposure to prevent HPS in an adult animal model of HPS following a respiratory (i.e., intranasal) challenge with ANDV. The intranasal (i.n.) route was used to more closely mimic a common route of natural exposure. To confirm that ANDV was indeed sensitive to ribavirin, in vitro cell culture assays were run using $10-70 \mu \mathrm{g} / \mathrm{mL}$ of ribavirin. During the process, a quick and effective method of screening for infectivity/replication was developed and is reported herein. Once susceptibility was confirmed, Syrian hamsters were infected i.n. with ANDV and treated with 50, 100 or $200 \mathrm{mg} / \mathrm{kg} /$ day of ribavirin, beginning between 1 and 12 days after infection. Efficacy and toxicity were tested simultaneously. These studies show the definite potential ribavirin has as an effective antiviral treatment for HPS.

\section{Results and Discussion}

Broad spectrum antiviral therapies against the hemorrhagic fever viruses such as the New World hantaviruses is a priority given their high lethality and lack of available FDA-approved treatments [45]. Whether through a natural outbreak or a bioterrorism event, this group of viruses yields little time for medical intervention post-onset, and thus require rapid treatment. Case-fatality for HPS caused by the most prevalent North American and South American hantaviruses, SNV and ANDV, respectively, is $30 \%-50 \%$ even in modern intensive care facilities. This is the second highest mortality associated with hemorrhagic fever viruses. Only the filoviruses exceed these mortality rates in causing mortality up to 90\% in some outbreaks in sub-Saharan Africa. Ribavirin has been employed in treatment of several human diseases caused by different hemorrhagic fever viruses including the Old World hantavirus, HTNV [41,46,47], and herein we provide an extensive evaluation of its efficacy in the i.n. challenge model of lethal ANDV infection of adult hamsters. 


\subsection{In Vitro Analyses of Ribavirin Inhibition in a Novel Viral Spread Assay and Titer Reduction Assay}

We developed a novel viral spread assay to provide a rapid assessment of the potency of ribavirin in vitro over a range of concentrations. Vero E6 cells were infected with ANDV virus, allowed to adsorb for $1 \mathrm{~h}$ before removing the media and washing two times with PBS. Liquid cell culture media containing from $10-70 \mu \mathrm{g} / \mathrm{mL}$ of ribavirin or media alone was added to the flasks. Cells were fixed from 4 to 10 days after infection and immunostained using an antibody against the glycoprotein. Flasks containing ANDV alone were used for comparison to flasks containing the varying concentrations of ribavirin (Figure 1). In the absence of inhibition, the pattern of immunostaining had a comet-like appearance consisting of an initial focus and then a "tail" of satellite foci presumably resulting from virions released into the media and spread by directional convection currents in the flask. Flasks were scored as either negative (absence of comets), + (few comets), ++ (some comets but less than ANDV alone) or +++ (identical to that of ANDV infected flasks) (Table 1). In the mock-treated cultures, flasks on 4-5 days post-infection showed no viral antigen. On day 5, virus was becoming visible as tiny punctuate spots on the monolayer. By day 7, the virus was visible in the form of comets throughout the cell monolayer. At days 8-10, the viral comets became longer and more numerous until the entire monolayer was completely infected by ANDV (Figure 1). At concentrations of $40 \mu \mathrm{g} / \mathrm{mL}$ and above, ribavirin showed a complete inhibition of virus comets. At 10,20 and $30 \mu \mathrm{g} / \mathrm{mL}$, ribavirin showed a delayed appearance of virus comets (days 7-9) suggesting that replication was being repressed but not completely inhibited (Figure 1, Table 1). However, while this assay is novel, it is only qualitative not quantitative so in order to determine the effective inhibitory concentration, a traditional yield reduction assay was also performed.

Figure 1. Visual representation of antiviral activity of ribavirin in a comet spread assay with Andes virus (ANDV). Representative culture flasks stained for the presence of the ANDV glycoprotein are shown different days post-infection with ANDV in the presence or absence of ribavirin. ANDV staining on Day 10 at 20 and $40 \mu \mathrm{g} / \mathrm{mL}$ ribavirin shows an inhibition of staining or spread at $40 \mu \mathrm{g} / \mathrm{mL}$ ribavirin but not $20 \mu \mathrm{g} / \mathrm{mL}$ ribavirin. With ANDV alone, an increase in the level of stain is observed over Days 5-10.
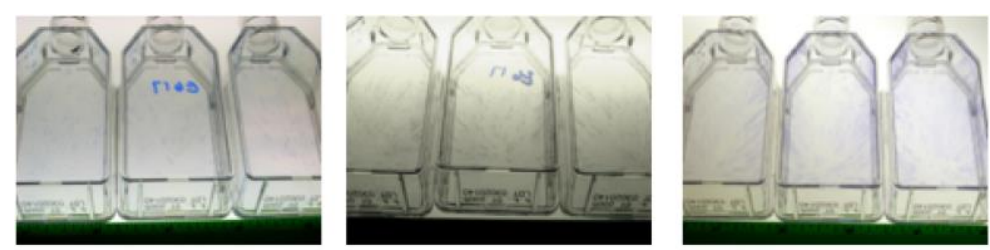

DAY 5 ANDV ALONE

DAY 7ANDV ALONE

DAY 9ANDV ALONE
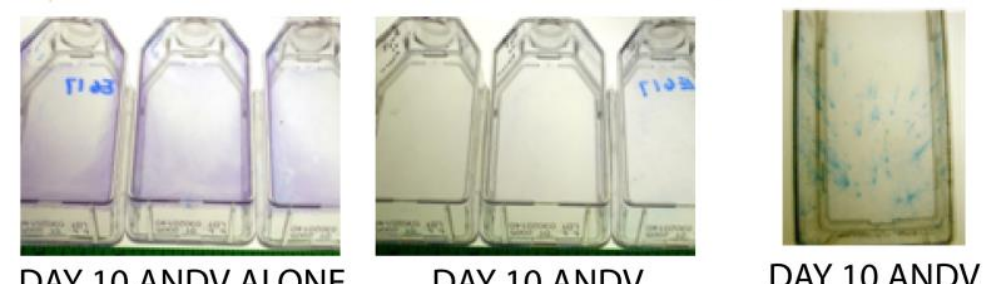

DAY 10 ANDV ALONE 
Table 1. Qualitative assessment of antiviral activity in a novel comet assay *.

\begin{tabular}{lccccccc}
\hline Concentration & Day 4 & Day 5 & Day 6 & Day 7 & Day 8 & Day 9 & Day 10 \\
\hline ANDV alone & - & +++ & +++ & +++ & +++ & +++ & +++ \\
$10 \mu \mathrm{g} / \mathrm{mL}$ & - & - & - & ++ & ++ & ++ & ++ \\
$20 \mu \mathrm{g} / \mathrm{mL}$ & - & - & - & + & + & ++ & ++ \\
$30 \mu \mathrm{g} / \mathrm{mL}$ & - & - & - & - & - & + & + \\
$40 \mu \mathrm{g} / \mathrm{mL}$ & - & - & - & - & - & - & - \\
$50 \mu \mathrm{g} / \mathrm{mL}$ & - & - & - & - & - & - & - \\
$60 \mu \mathrm{g} / \mathrm{mL}$ & - & - & - & - & - & - & - \\
$70 \mu \mathrm{g} / \mathrm{mL}$ & - & - & - & - & - & - & - \\
\hline
\end{tabular}

* -, no comets formed; +, few comets formed; ++, comets formed not equal to ANDV; +++, comets equal to ANDV alone.

A titer reduction assay was conducted with supernatant from Vero E6 cells infected with ANDV and treated with varying amounts of ribavirin from $0-70 \mu \mathrm{g} / \mathrm{mL}$. Two $1 \mathrm{~mL}$ aliquots of supernatant were collected daily for 10 days. Aliquots were frozen at $-80{ }^{\circ} \mathrm{C}$ until a plaque assay could be performed. ANDV alone showed steady growth until maximum growth was reached at 7 days post-infection and then virus output leveled off and remained steady through the rest of the course of the infection (Figure 2). Ribavirin reduced viral titer starting at $10 \mu \mathrm{g} / \mathrm{mL}$; the $10 \mu \mathrm{g} / \mathrm{mL}$ dose titer levels remained within one $\log$ of ANDV over the time course. At doses of $40 \mu \mathrm{g} / \mathrm{mL}$ and higher, ribavirin showed the most significant level of inhibition when compared to ANDV; the difference being a thousand fold or higher (Figure 2). The $50 \%$ effective concentration $\left(\mathrm{EC}_{50}\right)$ for inhibition of ANDV on day 5 was $30 \mu \mathrm{g} / \mathrm{mL}$, which was similar to that observed in the visual comet spread assay.

Figure 2. Antiviral activity of ribavirin in a titer reduction assay with ANDV. Vero E6 cells were infected with ANDV and after specific days post-infection viral supernatant was analyzed for viral titer. The viral titers at various concentrations $(0-70 \mu \mathrm{g})$ of ribavirin are presented.




The viral spread assay presented herein provides a new and effective tool for relatively quick screening of small molecules and biologics. With viruses like the hantaviruses, screening these compounds by traditional methods such as yield reduction is very time consuming, typically taking up to a month to complete. Another positive aspect of this assay is that the absence of comet formation generally correlates to a 1,000 fold reduction in viral titer when compared to yield reduction assays. The data suggests that ANDV was sensitive to ribavirin. The data also indicates that the spread assay while only qualitative does match with the more quantitative titer reduction assay. Thus, the viral spread assay allows candidate antivirals to be quickly screened for efficacy before undergoing the time-consuming yield reduction assay. A caveat is that the relatively large volume of media used in the comet inhibition assay necessitates that orders of magnitude more inhibitor be used to match the concentrations in a 96 or 384 well format.

\subsection{Ribavirin Efficacy in the Syrian Hamster Model of HPS Following Intranasal Challenge}

In the following experiments, Syrian hamsters were infected i.n. with 4,000 plaque forming units (pfu) with ANDV. The i.n. route of virus challenge was used to more closely mimic the respiratory route of natural exposure. Also, i.n. challenge results in a prolonged incubation period relative to parenteral routes such as intraperitoneal or intramuscular. The mean time-to-death in adult Syrian hamsters after i.n. exposure is 14-26 days depending on the dose [14,20], whereas the intraperitoneal and intramuscular routes result in lethal infections between 1 and 2 weeks. We and others have observed that, regardless of route of exposure, signs of disease are absent until approximately 1-2 days before the animal becomes moribund or succumbs. These signs include dyspnea, tachycardia, lethargy, and occasionally epistaxis [20]. In our initial experiment, groups of hamsters were administered ribavirin at either $50 \mathrm{mg} / \mathrm{kg} /$ day, $100 \mathrm{mg} / \mathrm{kg} /$ day, $200 \mathrm{mg} / \mathrm{kg} /$ day, or mock treated with PBS, starting 1 day post-infection and continued for 21 days. Ribavirin was given twice a day with i.p. injections approximately $10 \mathrm{~h}$ apart. Animals were monitored for signs of disease and euthanized when the animals met predetermined criteria (e.g., dyspnea, immobility). To control for drug toxicity, an additional four groups of three uninfected hamsters were treated with $50 \mathrm{mg} / \mathrm{kg} / \mathrm{day}, 100 \mathrm{mg} / \mathrm{kg} / \mathrm{day}, 200 \mathrm{mg} / \mathrm{kg} / \mathrm{day}$, or PBS as described above. On day 5, hamsters that were receiving $200 \mathrm{mg} / \mathrm{kg} / \mathrm{day}$, both in the infected and uninfected group, started to show signs of illness: weight loss/wasting, diarrhea, and lethargy (Figure 3A,B). Eight animals, 6 infected with ANDV and 2 uninfected, were euthanized due to toxicity caused by ribavirin at this concentration in hamsters. Toxicity of ribavirin in hamsters at $200 \mathrm{mg} / \mathrm{kg} / \mathrm{day}$ in hamsters has been observed by another group testing ribavirin in hamsters [38]. Uninfected hamsters in either 100 or $50 \mathrm{mg} / \mathrm{kg} /$ day groups did not show these signs of drug-induced disease. Untreated hamsters infected with ANDV developed lethal HPS starting on days 12-24 post-infection (mean day-to-death $=17.6$ days). None of the animals receiving ribavirin at 50 or $100 \mathrm{mg} / \mathrm{kg} / \mathrm{day}$ or the uninfected control animals showed signs of illness indicating that ribavirin at 50 or $100 \mathrm{mg} / \mathrm{kg} /$ day was capable of preventing death due to HPS after an i.n. challenge (Figure 3B). 
Figure 3. Survival curve of hamsters with mock or ribavirin-treatment following infection with ANDV. (A) To test drug toxicity, hamsters were given either 50, 100, or $200 \mathrm{mg} / \mathrm{kg} / \mathrm{day}$ of ribavirin, or mock treated (no ribavirin), for 21 days and then observed thru 35 days post-infection; (B) Hamsters were challenged with 4,000 pfu by the i.n. route and, starting on day 0 , given either 50,100 , or $200 \mathrm{mg} / \mathrm{kg} /$ day of ribavirin, or mock treated, for 21 days. Animals were observed for signs of disease for 35 days after challenge. Treatment with ribavirin protected animals after infection with ANDV at $100 \mathrm{mg} / \mathrm{kg}$ and $50 \mathrm{mg} / \mathrm{kg}$ doses ( $p=0.02$ and 0.03 , respectively). There was no difference between animals given $200 \mathrm{mg} / \mathrm{kg}$ after infection and animals infected without treatment, which confirms the above findings that ribavirin is lethal at a dose of $200 \mathrm{mg} / \mathrm{kg}$; (C) Survival curve of hamsters mock or treated with $50 \mathrm{mg} / \mathrm{kg} /$ day ribavirin starting at days $6,8,10,12$, or 14 following infection with ANDV. All treatment groups had significantly higher survival compared to untreated ( $p<0.05$ ); (D) Animals receiving treatment began at either at day 6 or 10 post-infection survived infection with ANDV for 11, 15 or 21 days. All treatment groups had significantly higher survival compared to untreated $(p<0.01)$ Survival analyses were performed by computing pair-wise comparisons to controls using the nonparametric Mantel-Cox test and the resulting $p$-values were adjusted using the Holm-Bonferroni method for multiple comparisons.
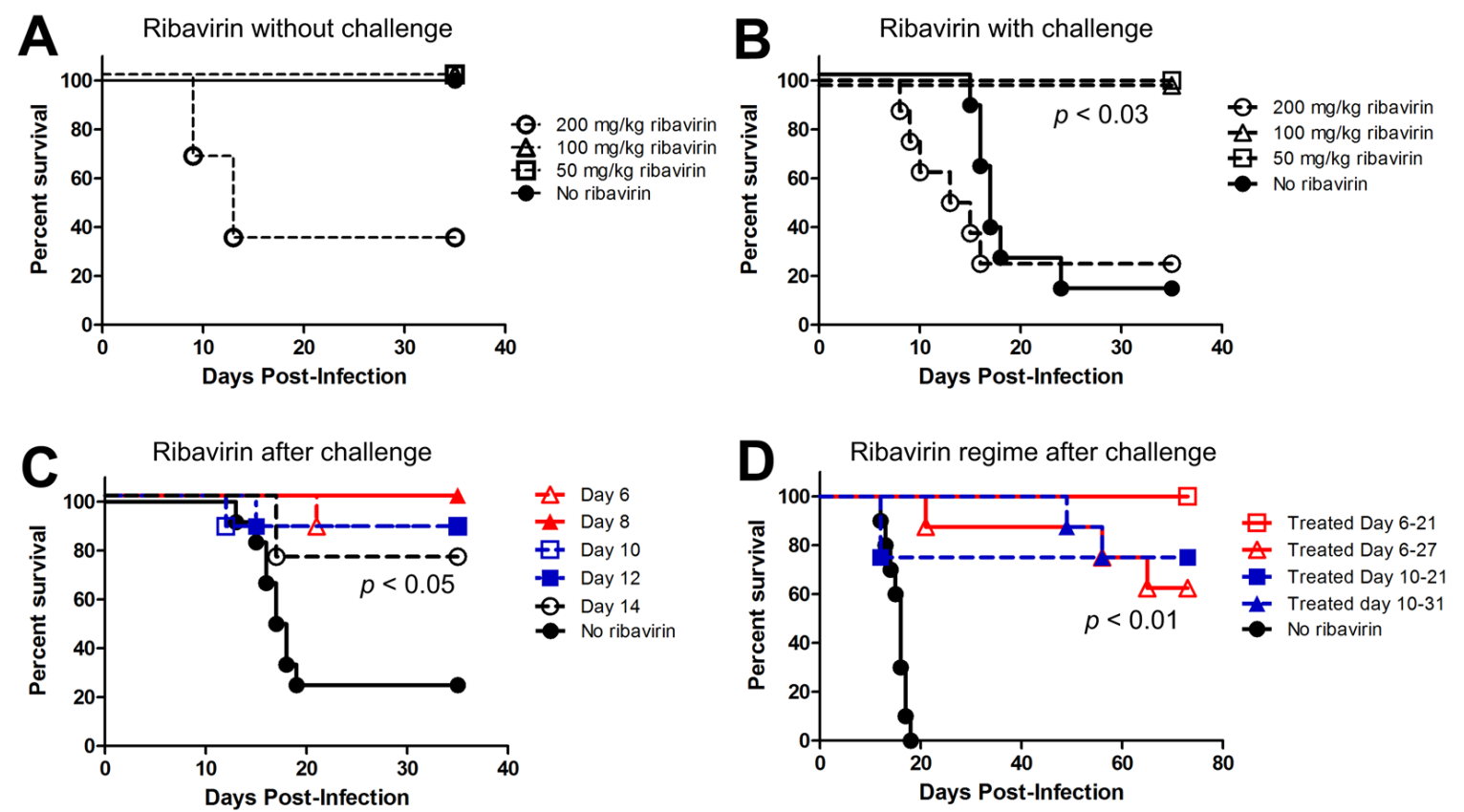

Analysis of serum samples collected after challenge demonstrated that ribavirin treatment starting 1 day after challenge reduced or completely abolished the presence of live virus. No virus was detected 7 days after challenge in all groups (data not shown). By 14 days after infection, the No Treatment and $50 \mathrm{mg} / \mathrm{kg} /$ day ribavirin groups showed the presence of virus in the sera (Figure 4A). Virus was not detected in the sera of the 100 or $200 \mathrm{mg} / \mathrm{kg} /$ day treatment groups at any time after challenge (data not shown). By 21 days, all of the surviving animals except one in the No Treatment group had cleared the viremia. These results suggested the higher concentrations of ribavirin completely inhibited ANDV replication in vivo. Animals treated with $50 \mathrm{mg} / \mathrm{kg} /$ day were only partially protected from virus replication. To ensure that those animals that survived did so because of repression of virus replication, 
and not because of a lack of virus exposure, ELISA's were performed to measure anti-ANDV nucleocapsid antibody levels. All animals which were exposed to virus were positive for anti-nucleocapsid IgG antibody by enzyme-linked immunosorbent assay (ELISA), whereas all day-7 prebleeds were negative, indicating that all the animals were indeed exposed to ANDV (Figure 5). All animals that were not exposed to ANDV did not show the presence of any viral titer or any evidence of seroconversion indicating that cross contamination of cages in the study room did not occur.

Figure 4. Viremia in ANDV-exposed hamsters treated with ribavirin. Sera collected from ANDV-exposed hamsters from the experiments shown in Figure 3 were evaluated for the presence of infectious ANDV by plaque assay. (A) ANDV titers in hamster sera collected 2 or 3 weeks after i.n. challenge with ANDV from the $50 \mathrm{mg} / \mathrm{kg} / \mathrm{day}$ and no treatment groups are shown. Note that the $100 \mathrm{mg} / \mathrm{kg} / \mathrm{day}$ sera were all negative for ANDV on all time points (data not shown); (B) ANDV titers in hamster sera collected 1 or 2 weeks after i.n. challenge with ANDV. Ribavirin treatment was started on days 6, 8, 10, 12, or 14 days after challenge; (C) ANDV titers in hamster sera collected 1 or 2 weeks after i.n. challenge with ANDV. Ribavirin treatment started on day 6 or 10 and continued for 11, 15, or 21 days. Red symbols represent hamsters that ultimately developed lethal infections. Green symbols indicate animals that succumbed after anesthesia or for other causes other than HPS. Lines indicate mean ANDV titers for each group.
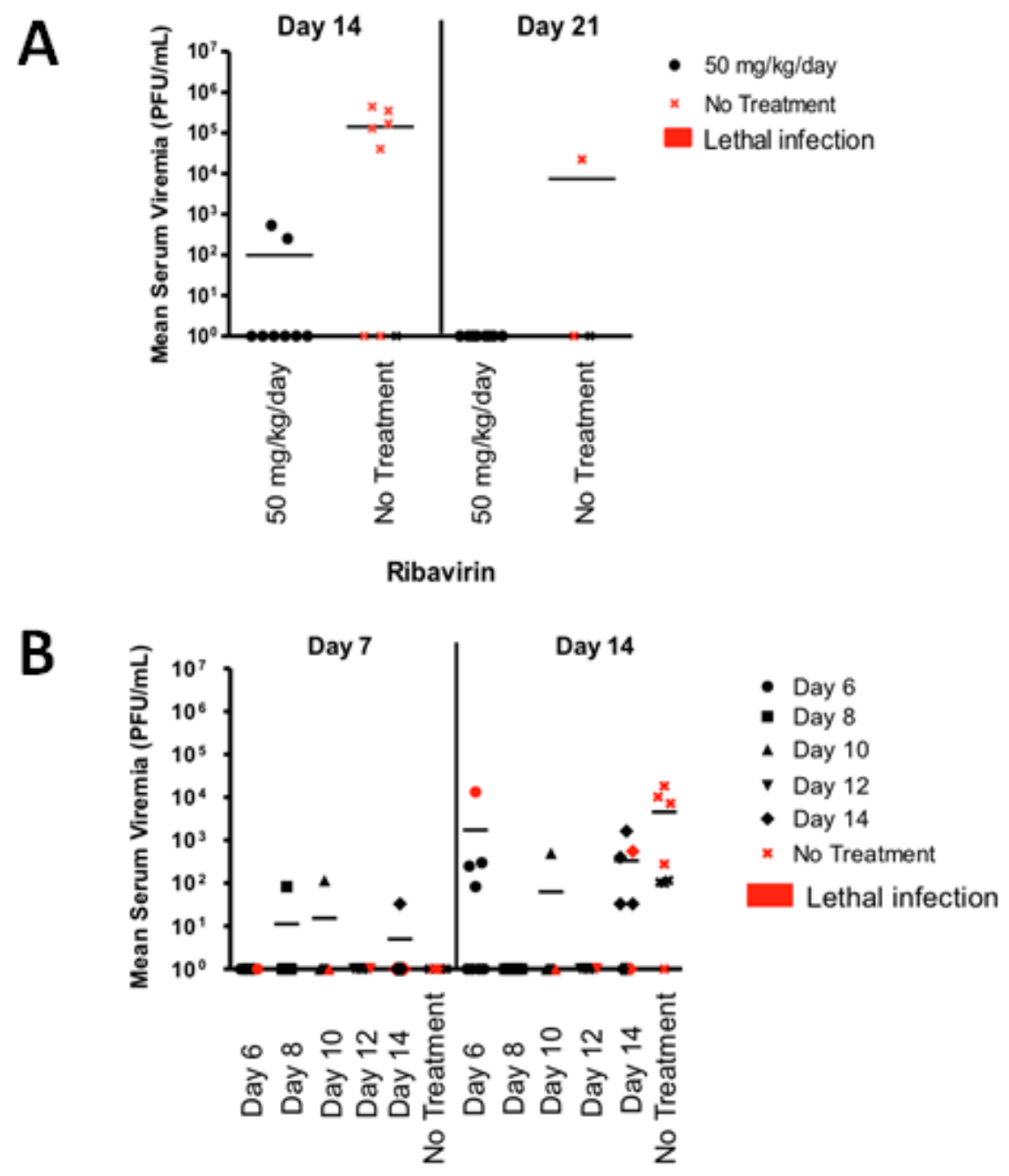
Figure 4. Cont.



Figure 5. ELISA titers on day 35 post-ANDV infection of hamster. Titer (y-axis) is shown on Day 35 in sera collected from measurement by ELISA with antibody to the nucleocapsid protein. Various treatment and control (no treatment) groups (X-axis) are shown.

\section{Anti-nucleocapsid ELISA Day 35 Serum}

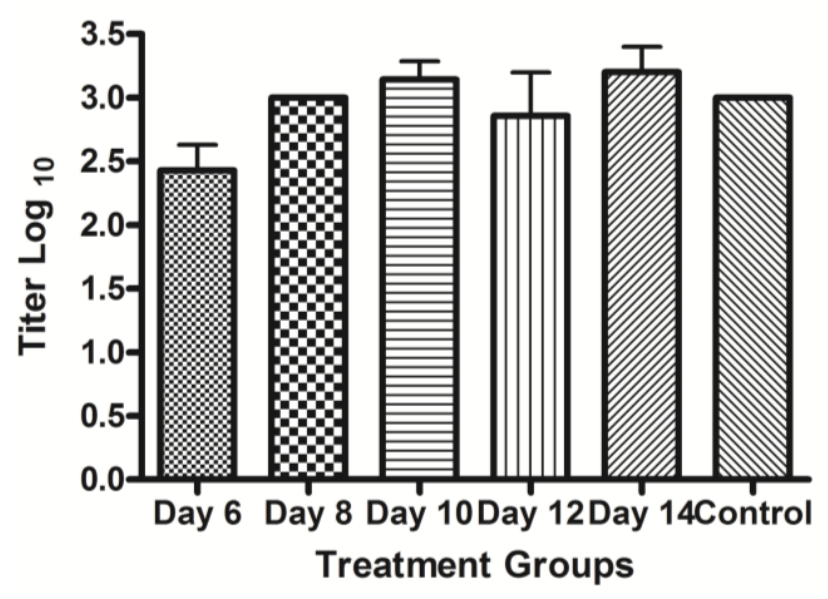

\subsection{Last Effective Day Post-Exposure for Treating HPS}

Since a dose of $50 \mathrm{mg} / \mathrm{kg} /$ day was effective at preventing HPS, we asked if this dose would be effective if begun later after ANDV challenge. Groups of eight hamsters were challenged with ANDV as described above. Ribavirin treatment was started at 6, 8,10,12 or 14 days after challenge. Ribavirin was given as previously described, two times a day approximately $10 \mathrm{~h}$ apart, and given for a full 21 days. Animals that were not treated with ribavirin were given PBS on the same schedule as the treated groups (Figure 3C). Untreated animals became ill and were euthanized starting as early as day 12 . Three animals not receiving ribavirin survived (75\% lethal) indicating the challenge was not as lethal in previous experiments (88\% lethal). While lethal infection occurred in all groups except for those animals receiving treatment on day 8 , treatment starting as late as day 12 was effective $(p<0.05)$ at preventing HPS. Treatment starting on day 14 prevented death in $75 \%$ of the animals $(p=0.034)$. 
Seven days post-challenge, the majority of animals in all treatment groups were negative for infectious ANDV (Figure 4B). Fourteen days post challenge, approximately half of the animals in the Day 6, 14, and No Treatment groups showed signs of viremia. Twenty-one days after challenge, all of the surviving hamsters were negative for the presence of infectious ANDV (data not shown). This suggests that suppression of virus replication after infection can prevent HPS and allow the animals to clear infectious virus. Serum from 35 days post-infection, but not the day-7 prebleeds, showed the presence of anti-ANDV nucleocapsid antibodies in all groups, treated and untreated, suggesting that ANDV infection occurred in all exposed hamsters (Figure 5). Thus, ribavirin at $50 \mathrm{mg} / \mathrm{kg} / \mathrm{day}$ administered as late as 12 days after i.n. exposure is capable of preventing HPS in the hamster model. Day 12 is just 5 days before the mean time-to-death, 17.6 days. The onset of clinical signs is generally 1-2 days before the mean day-to-death.

\subsection{Confirming That Ribavirin can Be Used to Prevent HPS even When Treatment Starts 6-10 Days after a Respiratory Exposure}

To confirm that late administration of ribavirin could confer protection against an i.n. challenge, and to test the possibility that the duration of treatment could be reduced; groups of eight to ten hamsters were infected i.n. with 4,000 pfu of ANDV. Ribavirin was administered at $50 \mathrm{mg} / \mathrm{kg} / \mathrm{day}$ as before between days 6-21 (15 days), 6-27 (21 days) or between 10-21 (11 days) and 10-31 (21 days) days post-infection. Severe disease (requiring euthanasia) was first observed on day 12 and continued thru day 17 with the mean-time-to-death being 15.4 days. Two animals in the Day 10 group (10-21) developed HPS on day 12 with the remaining animals showing no signs of illness. All animals receiving treatment between Days 6-21 and most of the animals treated between Days 6-27 remained healthy and did not develop HPS (Figure 3D). To look for evidence of long-term sequelae [48], this experiment was continued for 10 weeks. Unexpectedly, two hamsters in the Days 6-21 group and two in the Days 10-21 group succumbed to illness beginning at 49. Necropsies revealed liver necrosis with signs of regeneration (data not shown). Viral antigen was not found within the liver tissue as measured by immunohistochemistry (data not shown), suggesting that the hamsters died because of liver failure of unknown etiology, and not hantavirus infection. This experiment confirmed that ribavirin treatment starting as late as day 10 post exposure, and administered for as few as 11 days, could prevent mortality due to HPS (survival analysis compared to untreated, $p<0.01$ ). Due to the toxicities of this drug, further investigations to determine the minimal duration of ribavirin treatment to prevent HPS are warranted.

Untreated animals and animals receiving ribavirin between days 10-21, that died around day 12 due to HPS (Figure 3D), had detectable viral titers on day 7 (Figure 4C). By day 14, a fraction of animals all groups had detectable levels of ANDV in the serum as measured by plaque assay. By day 21 there was no detectable infectious virus in any of the treated animals (data not shown). On day 35 and day 73, which was the end point of the experiment, none of the ribavirin treated animals showed the presence of virus (data not shown). As observed in earlier experiments, serum from 35 days post-infection, but not the day-7 prebleeds, showed the presence of anti-ANDV nucleocapsid antibodies in all groups, treated and untreated, suggesting that ANDV infection occurred in all exposed hamsters (Figure 5). 


\section{Experimental}

\subsection{Viruses and Cells}

ANDV strain Chile-917869 [14] was propagated in Vero E6 cells (Vero C1008; ATCC CRL 1586). Cells were maintained in Eagle's minimum essential medium with Earle's salts (EMEM) containing $10 \%$ fetal bovine serum (FBS), $10 \mathrm{mM}$ HEPES, pH 7.4, and antibiotics (penicillin [100 U/mL], streptomycin $[100 \mu \mathrm{g} / \mathrm{mL}]$, gentamicin sulfate $[50 \mu \mathrm{g} / \mathrm{mL}]$ ) in a $5 \% \mathrm{CO}_{2}$ incubator at $37{ }^{\circ} \mathrm{C}$. ANDV passage 2, twice-plaque-purified virus stock preparation, was previously described [14].

\subsection{Virus Yield Reduction Assay}

The antiviral activity of ribavirin was evaluated by a plaque reduction assay in Vero E6 cells infected with ANDV strain Chile-917869. Six-seven day old confluent Vero E6 cells grown in T150 flasks were infected with ANDV at a multiplicity of infection of 0.1 followed by absorption for $1 \mathrm{~h}$. After removing virally infected media and washing the cells in PBS, the media was replaced with complete EMEM (cMEM) containing ribavirin (ICN Pharmaceuticals, Costa Mesa, CA, USA) at concentrations ranging from $0-70 \mu \mathrm{g} / \mathrm{mL}$ and the cells were incubated at $37{ }^{\circ} \mathrm{C}$ and $5 \% \mathrm{CO}_{2}$. Every day $2 \mathrm{~mL}$ of supernatant were harvested from each flask and frozen at $-80{ }^{\circ} \mathrm{C}$ until they were subjected to plaque assay to measure progeny virus released into the supernatant.

\subsection{Serum Plaque Assay}

Hantaviral plaque assays to measure infectious virus in sera were performed as previously described [14]. Briefly, serum samples were centrifuged at $10,000 \times g$ for $10 \mathrm{~s}$ to pellet any debris before dilution. Supernatants were used to prepare 1:10 dilutions. Once sample dilutions were made, $200 \mu \mathrm{L}$ was added to each well of a 6-well Costar plate containing 7 day old Vero E6 cells. After a $1 \mathrm{~h}$ adsorption at $37{ }^{\circ} \mathrm{C}$ and $5 \% \mathrm{CO}_{2}, 3 \mathrm{~mL}$ overlay medium was added to each well as previously described [14]. Plates were incubated at $37{ }^{\circ} \mathrm{C}$ and $5 \% \mathrm{CO}_{2}$ for 7 days at which point they were stained with a $2 \mathrm{~mL} /$ well overlay medium containing 5\% fetal bovine serum and 5\% neutral red solution (Invitrogen, Carlsbad, CA, USA). Plates were incubated for an additional 3 days at $37{ }^{\circ} \mathrm{C}$ or until plaques were visible and countable.

\subsection{Viral Spread (Comet) Assay}

The antiviral activity of ribavirin was evaluated by a virus spread inhibition assay in Vero E6 cells infected with ANDV strain Chile-917869. One week-old confluent Vero E6 cells grown in T25 flasks were infected with ANDV at $15 \mu \mathrm{L}$ of a $3.6 \times 107 \mathrm{pfu} / \mathrm{mL}$ stock in $10 \mathrm{~mL}$ followed by adsorption for $1 \mathrm{~h}$. An additional $10 \mathrm{~mL}$ of cMEM media was added to the flask at the end of the hour incubation period. The flasks were placed in a $37{ }^{\circ} \mathrm{C}$ and $5 \% \mathrm{CO}_{2}$ incubator with the plate containing the flasks set at a slight angle, which influenced the direction of the comet-like immunostaining pattern. Flasks were fixed in $2 \mathrm{~mL}$ of a $50 \%$ methanol and acetone mixture for $10 \mathrm{~min}$ and washed with $1 \mathrm{~mL}$ of PBS twice. Cells were immunostained for the presence of viral antigen using antibody $\mathrm{mAb}-3 \mathrm{~d} 7$, which is directed toward the $\mathrm{G}_{\mathrm{c}}$ glycoprotein. After removal of the PBS, $1 \mathrm{~mL}$ of the primary antibody solution (3\% fetal 
bovine serum and a 1:500 dilution of $\mathrm{mAb}-3 \mathrm{~d} 7$ in PBS) was added to the flasks which were then placed on a rocker at room temperature for $2 \mathrm{~h}$. The antibody mixture was subsequently removed from the flasks and the monolayer was washed with $2 \mathrm{~mL}$ of PBS 2 times. One $\mathrm{mL}$ of the secondary antibody mixture (3\% fetal bovine serum, a 1:1,000 dilution of HPO-Bethyl G and M IgG1 and PBS) was added to the flasks and allowed to rock at room temperature for one and one half hours. The secondary antibody mixture was then removed from the flasks and the flasks were washed with $2 \mathrm{~mL}$ of PBS 2 times. One mL of substrate solution, KPL-True Blue Peroxidase Substrate, (KPL, Kirkegaard and Perry Laboratories Inc., Gaithersburg, MD, USA) was added to each flask and allowed to develop for $10 \mathrm{~min}$. The substrate solution was removed and washed with $2 \mathrm{~mL}$ of distilled water. After removal of the water, flasks were air-dried and examined for the presence of virally stained cells. Viral inhibition was determined by comparing uninfected flasks with flasks containing antiviral compounds. Compounds that were inhibitory did not show the presence of viral "comets"- showing spread of the ANDV from cell to cell.

\subsection{Intranasal Infection of Hamsters with ANDV}

Syrian female hamsters, 6-8 week old, were obtained from Harlan (Indianapolis, IN, USA) and were used for all animal studies. Hamsters were routinely used within 1-2 weeks after shipment from the vendor. Hamsters younger than 7 weeks at time of challenge were not used in this study because we, and others, have observed a shorter incubation time (i.e., 10-13 days versus 14-26 days) following i.n. challenge in the younger hamsters (unpublished data and $[18,19]$ ). Hamsters were identified by an ear-tag. Hamsters were bled by vena cava at day 7 prior to infection; $0.5 \mathrm{~mL}$ of blood was taken. Hamsters were moved into the biosafety level 4 laboratory (BSL-4) to acclimate at least 3 days prior to infection. Animals were anesthetized by isoflurane and infected i.n. with 4,000 pfu of ANDV in $50 \mu \mathrm{L}$ of PBS delivered as $25 \mu \mathrm{L}$ per naris. Control animals were given $50 \mu \mathrm{L}$ of PBS without ANDV. Hamsters were injected with $0.1 \mathrm{~mL} / 100 \mathrm{~g}$ of body weight with ketamine-acepromazine-xylazine mixture before bleeds $(0.5 \mathrm{~mL})$ on $7,14,21$, and 35 days post-infection. Starting one day post-infection hamsters were given $200 \mathrm{mg} / \mathrm{kg} /$ daily, $100 \mathrm{mg} / \mathrm{kg} /$ daily or $50 \mathrm{mg} / \mathrm{kg} /$ daily of ribavirin dissolved in PBS and filter sterilized as two injections in a volume of $0.5 \mathrm{~mL}$ approximately $10 \mathrm{~h}$ apart. Hamsters receiving no treatment were injected with filtered PBS in the same volume and according to the same dosing schedule as the treated hamsters. Hamsters were monitored two to three times daily. All work involving ANDV infected hamsters was performed in a BSL-4. Research was conducted in compliance with the animal welfare act and other federal statutes and regulations relating to animals and experiments involving animals adhered to the principles stated in the Guide for the Care and Use of Laboratory Animals, National Research Council, 2011. The facility where this research was conducted is fully accredited by the Association for Assessment and Accreditation of Laboratory Animal Care International.

\subsection{Post-Exposure Prophylaxis for Treating HPS}

Post-exposure prophylaxis hamsters were given injections of ribavirin $50 \mathrm{mg} / \mathrm{kg} /$ daily divided into two equal injections (10 h apart) beginning at 6, 8, 10, 12, or 14 after challenge and continuing for 21 days. Animals that were not treated with ribavirin were given PBS on the same schedule as the treated groups. Groups of eight hamsters were challenged with ANDV as described above. Hamsters were 
observed for 35 days at which point survivors were euthanized. The second iteration of post-exposure prophylaxis hamsters were given injections of ribavirin $50 \mathrm{mg} / \mathrm{kg} /$ daily divided into two equal injections continuing for either 21 days or up until day 21. Hamsters were observed for 73 days at which point survivors were euthanized. Research was conducted in compliance as stated above in Section 3.5.

\subsection{ELISA}

Antibodies to ANDV nucleocapsid cross-react with Puumala virus nucleocapsid. This cross-reactivity makes it possible to use a Puumala virus nucleocapsid-based ELISA to detect antibodies to the ANDV nucleocapsid. Anti-nucleocapsid ELISAs were performed as described previously [14,49]. The plasmid pPUUSXdelta (kindly provided by F. Elgh) was expressed in Escherichia coli BL21 (DE3) cells (Novagen, Madison, WI, USA) to generate histidine-tagged truncated Puumala virus nucleocapsid protein. The protein was affinity purified using a Ni-nitrilotriacetic acid column (Qiagen, Valencia, CA, USA). Hamster sera was gamma irradiated on dry ice ( 3 million rad from a ${ }^{60} \mathrm{C}$ source) and heat inactivated before being tested in ELISA.

\subsection{Statistical Analyses}

Survival analyses were performed by computing pair-wise comparisons to controls using the nonparametric Mantel-Cox test using the program $\mathrm{R}$ (version 2.13.0). The resulting $p$-values are reported after a posteriori adjustments using the Holm-Bonferroni method for multiple comparisons.

\section{Conclusions}

Clinical studies have shown that, if begun early in the disease process, ribavirin can be effective against hantaviruses causing HFRS $[39,41]$. Clinical trials for ribavirin for HPS have been limited and inconclusive $[42,43]$. The efficacy of ribavirin in treatment of HPS in hamsters will hopefully provide the incentive to open large clinical studies across borders throughout the Americas. This research provides further evidence that this drug can be effectively used in treating this rapid and life-threatening disease if given before onset of symptoms. Here we have shown significant efficacy if treatment began as late as 14 days after exposure, only days before signs of disease. Ribavirin has known side effects, such as hemolytic anemia and potential teratogenicity, which make therapy difficult and potentially dangerous $[45,50]$. The shorter the period of time those patients remain on treatment, the less chance that they will experience detrimental side effects. The use of an antiviral therapeutic starting on day 10 and administered for only 11 days in the hamster-ANDV model without observing viral re-emergence is a remarkable finding. This suggests that the immune system is capable of clearing the virus if replication can be inhibited before high levels of viremia occur. The ANDV/hamster i.n. challenge studies reported herein, combined with ANDV/hamster i.p. challenge studies reported by others [18], provide health care workers and scientists information that can be used for decision making as to whether or not ribavirin will be of clinical benefit following a needle stick, animal bite, or other event with a high probability of hantavirus exposure. Future research aims to identify noninvasive methods to detect early signs of disease in the hamster model of HPS. Such methods would allow for more accurate trigger-to-treat times for studies of candidate therapeutics. 


\section{Acknowledgments}

This work was supported by NIH Grant R21 AI064499-01 to CBJ and JWH and by the U.S. Army Medical Research and Material Command, Military Infectious Disease Research Program, Program Area T. Opinions, interpretations, conclusions, and recommendations are ours and are not necessarily endorsed by the U.S. Army or the Department of Defense.

\section{Conflicts of Interest}

The authors declare no conflict of interest.

\section{References}

1. Jonsson, C.B.; Figueiredo, L.T.; Vapalahti, O. A global perspective on hantavirus ecology, epidemiology, and disease. Clin. Microbiol. Rev. 2010, 23, 412-441.

2. Schmaljohn, C.; Hjelle, B. Hantaviruses: A global disease problem. Emerg. Infect. Dis. 1997, 3, 95-104.

3. Peters, C.J.; Simpson, G.L.; Levy, H. Spectrum of hantavirus infection: Hemorrhagic fever with renal syndrome and hantavirus pulmonary syndrome. Annu. Rev. Med. 1999, 50, 531-545.

4. Lee, H.W.; French, G.R.; Lee, P.W.; Baek, L.J.; Tsuchiya, K.; Foulke, R.S. Observations on natural and laboratory infection of rodents with the etiologic agent of Korean hemorrhagic fever. Am. J. Trop. Med. Hyg. 1981, 30, 477-482.

5. Tsai, T.F. Hemorrhagic fever with renal syndrome: Mode of transmission to humans. Lab. Anim. Sci. 1987, 37, 428-430.

6. Jonsson, C.B.; Hooper, J.; Mertz, G. Treatment of hantavirus pulmonary syndrome. Antiviral Res. 2008, 78, 162-169.

7. Padula, P.J.; Edelstein, A.; Miguel, S.D.; Lopez, N.M.; Rossi, C.M.; Rabinovich, R.D. Hantavirus pulmonary syndrome outbreak in Argentina: Molecular evidence for person-to-person transmission of Andes virus. Virology 1998, 241, 323-330.

8. Padula, P.J.; Edelstein, A.; Miguel, S.D.; Lopez, N.M.; Rossi, C.M.; Rabinovich, R.D. Epidemic outbreak of Hantavirus pulmonary syndrome in Argentina. Molecular evidence of person to person transmission of Andes virus. Medicina (B Aires) 1998, 58, 27-36.

9. Enria, D.; Padula, P.; Segura, E.L.; Pini, N.; Edelstein, A.; Posse, C.R.; Weissenbacher, M.C. Hantavirus pulmonary syndrome in Argentina. Possibility of person to person transmission. Medicina (B Aires) 1996, 56, 709-711.

10. Martinez, V.P.; Bellomo, C.; San Juan, J.; Pinna, D.; Forlenza, R.; Elder, M.; Padula, P.J. Person-to-person transmission of Andes virus. Emerg. Infect. Dis. 2005, 11, 1848-1853.

11. Wells, R.M.; Sosa Estani, S.; Yadon, Z.E.; Enria, D.; Padula, P.; Pini, N.; Gonzalez, D.V.M.; Mills, J.N.; Peters, C.J. Seroprevalence of antibodies to hantavirus in health care workers and other residents of southern Argentina. Clin. Infect. Dis. 1998, 27, 895-896. 
12. Wells, R.M.; Sosa, E.S.; Yadon, Z.E.; Enria, D.; Padula, P.; Pini, N.; Mills, J.N.; Peters, C.J.; Segura, E.L. An unusual hantavirus outbreak in southern Argentina: Person-to-person transmission? Hantavirus Pulmonary Syndrome Study Group for Patagonia. Emerg. Infect. Dis. 1997, 3, 171-174.

13. Toro, J.; Vega, J.D.; Khan, A.S.; Mills, J.N.; Padula, P.; Terry, W.; Yadon, Z.; Valderrama, R.; Ellis, B.A.; Pavletic, C.; et al. An outbreak of hantavirus pulmonary syndrome, Chile, 1997. Emerg. Infect. Dis. 1998, 4, 687-694.

14. Hooper, J.W.; Larsen, T.; Custer, D.M.; Schmaljohn, C.S. A lethal disease model for hantavirus pulmonary syndrome. Virology 2001, 289, 6-14.

15. Wahl-Jensen, V.; Chapman, J.; Asher, L.; Fisher, R.; Zimmerman, M.; Larsen, T.; Hooper, J.W. Temporal analysis of Andes virus and Sin Nombre virus infections of Syrian hamsters. J. Virol. 2007, 81, 7449-7462.

16. Campen, M.J.; Milazzo, M.L.; Fulhorst, C.F.; Obot Akata, C.J.; Koster, F. Characterization of shock in a hamster model of hantavirus infection. Virology 2006, 356, 45-49.

17. Safronetz, D.; Zivcec, M.; Lacasse, R.; Feldmann, F.; Rosenke, R.; Long, D.; Haddock, E.; Brining, D.; Gardner, D.; Feldmann, H.; et al. Pathogenesis and host response in Syrian hamsters following intranasal infection with Andes virus. PLoS Pathog. 2011, 7, e1002426.

18. Safronetz, D.; Haddock, E.; Feldmann, F.; Ebihara, H.; Feldmann, H. In vitro and in vivo activity of ribavirin against Andes virus infection. PLoS One 2011, 6, e23560.

19. Safronetz, D.; Ebihara, H.; Feldmann, H.; Hooper, J.W. The Syrian hamster model of hantavirus pulmonary syndrome. Antiviral Res. 2012, 95, 282-292.

20. Hooper, J.W.; Ferro, A.M.; Wahl-Jensen, V. Immune serum produced by DNA vaccination protects hamsters against lethal respiratory challenge with Andes virus. J. Virol. 2008, 82, 1332-1338.

21. Brocato, R.; Josleyn, M.; Ballantyne, J.; Vial, P.; Hooper, J.W. DNA vaccine-generated duck polyclonal antibodies as a postexposure prophylactic to prevent hantavirus pulmonary syndrome (HPS). PLoS One 2012, 7, e35996.

22. Brocato, R.L.; Josleyn, M.J.; Wahl-Jensen, V.; Schmaljohn, C.S.; Hooper, J.W. Construction and nonclinical testing of a puumala virus synthetic $m$ gene-based DNA vaccine. Clin. Vaccine Immunol. 2013, 20, 218-226.

23. Brown, K.S.; Safronetz, D.; Marzi, A.; Ebihara, H.; Feldmann, H. Vesicular stomatitis virus-based vaccine protects hamsters against lethal challenge with Andes virus. J. Virol. 2011, 85, 12781-12791.

24. Sun, Y.; Chung, D.H.; Chu, Y.K.; Jonsson, C.B.; Parker, W.B. Activity of ribavirin against Hantaan virus correlates with production of ribavirin-5'-triphosphate, not with inhibition of IMP dehydrogenase. Antimicrob. Agents Chemother. 2007, 51, 84-88.

25. Chung, D.H.; Sun, Y.; Parker, W.B.; Arterburn, J.B.; Bartolucci, A.; Jonsson, C.B. Ribavirin reveals a lethal threshold of allowable mutation frequency for Hantaan virus. J. Virol. 2007, 81, 11722-11729.

26. Severson, W.E.; Schmaljohn, C.S.; Javadian, A.; Jonsson, C.B. Ribavirin causes error catastrophe during Hantaan virus replication. J. Virol. 2003, 77, 481-488.

27. Jonsson, C.B.; Milligan, B.G.; Arterburn, J.B. Potential importance of error catastrophe to the development of antiviral strategies for hantaviruses. Virus Res. 2005, 107, 195-205. 
28. Kirsi, J.J.; North, J.A.; McKernan, P.A.; Murray, B.K.; Canonico, P.G.; Huggins, J.W.; Srivastava, P.C.; Robins, R.K. Broad-spectrum antiviral activity of 2-beta-D-ribofuranosylselenazole-4-carboxamide, a new antiviral agent. Antimicrob. Agents Chemother. 1983, 24, 353-361.

29. Medina, R.A.; Mirowsky-Garcia, K.; Hutt, J.; Hjelle, B. Ribavirin, human convalescent plasma and anti-beta3 integrin antibody inhibit infection by Sin Nombre virus in the deer mouse model. J. Gen. Virol. 2007, 88, 493-505.

30. Buys, K.K.; Jung, K.H.; Smee, D.F.; Furuta, Y.; Gowen, B.B. Maporal virus as a surrogate for pathogenic New World hantaviruses and its inhibition by favipiravir. Antivir. Chem. Chemother. 2011, 21, 193-200.

31. Huggins, J.W.; Kim, G.R.; Brand, O.M.; McKee, K.T., Jr. Ribavirin therapy for Hantaan virus infection in suckling mice. J. Infect. Dis. 1986, 153, 489-497.

32. Murphy, M.E.; Kariwa, H.; Mizutani, T.; Tanabe, H.; Yoshimatsu, K.; Arikawa, J.; Takashima, I. Characterization of in vitro and in vivo antiviral activity of lactoferrin and ribavirin upon hantavirus. J. Vet. Med. Sci. 2001, 63, 637-645.

33. Murphy, M.E.; Kariwa, H.; Mizutani, T.; Yoshimatsu, K.; Arikawa, J.; Takashima, I. In vitro antiviral activity of lactoferrin and ribavirin upon hantavirus. Arch. Virol. 2000, 145, 1571-1582.

34. Chung, D.H.; Strouse, J.J.; Sun, Y.; Arterburn, J.B.; Parker, W.B.; Jonsson, C.B. Synthesis and anti-Hantaan virus activity of N(1)-3-fluorophenyl-inosine. Antiviral Res. 2009, 83, 80-85.

35. Chung, D.H.; Kumarapperuma, S.C.; Sun, Y.; Li, Q.; Chu, Y.K.; Arterburn, J.B.; Parker, W.B.; Smith, J.; Spik, K.; Ramanathan, H.N.; et al. Synthesis of 1-beta-D-ribofuranosyl-3-ethynyl$[1,2,4]$ triazole and its in vitro and in vivo efficacy against Hantavirus. Antiviral Res. 2008, 79, 19-27.

36. Furuta, Y.; Takahashi, K.; Shiraki, K.; Sakamoto, K.; Smee, D.F.; Barnard, D.L.; Gowen, B.B.; Julander, J.G.; Morrey, J.D. T-705 (favipiravir) and related compounds: Novel broad-spectrum inhibitors of RNA viral infections. Antiviral Res. 2009, 82, 95-102.

37. Safronetz, D.; Falzarano, D.; Scott, D.P.; Furuta, Y.; Feldmann, H.; Gowen, B.B. Antiviral efficacy of favipiravir against two prominent etiological agents of hantavirus pulmonary syndrome. Antimicrob. Agents Chemother. 2013, 10, 4673-4680.

38. Gowen, B.B.; Wong, M.H.; Jung, K.H.; Sanders, A.B.; Mendenhall, M.; Bailey, K.W.; Furuta, Y.; Sidwell, R.W. In vitro and in vivo activities of T-705 against arenavirus and bunyavirus infections. Antimicrob. Agents Chemother. 2007, 51, 3168-3176.

39. Huggins, J.W.; Hsiang, C.M.; Cosgriff, T.M.; Guang, M.Y.; Smith, J.I.; Wu, Z.O.; LeDuc, J.W.; Zheng, Z.M.; Meegan, J.M.; Wang, Q.N.; et al. Prospective, double-blind, concurrent, placebo-controlled clinical trial of intravenous ribavirin therapy of hemorrhagic fever with renal syndrome. J. Infect. Dis. 1991, 164, 1119-1127.

40. Yang, Z.Q.; Zhang, T.M.; Zhang, M.V.; Zheng, Z.M.; Hu, Z.J.; Qu, C.F.; Xiang, J.M.; Huggins, J.W.; Cosgriff, T.M.; Smith, J.I. Interruption study of viremia of patients with hemorrhagic fever with renal syndrome in the febrile phase (English). Chin. Med. J. 1991, 104, 149-153.

41. Rusnak, J.M.; Byrne, W.R.; Chung, K.N.; Gibbs, P.H.; Kim, T.T.; Boudreau, E.F.; Cosgriff, T.; Pittman, P.; Kim, K.Y.; Erlichman, M.S.; et al. Experience with intravenous ribavirin in the treatment of hemorrhagic fever with renal syndrome in Korea. Antiviral Res. 2009, 81, 68-76. 
42. Chapman, L.E.; Ellis, B.A.; Koster, F.T.; Sotir, M.; Ksiazek, T.G.; Mertz, G.J.; Rollin, P.E.; Baum, K.F.; Pavia, A.T.; Christenson, J.C.; et al. Discriminators between hantavirus-infected and -uninfected persons enrolled in a trial of intravenous ribavirin for presumptive hantavirus pulmonary syndrome. Clin. Infect. Dis. 2002, 34, 293-304.

43. Mertz, G.J.; Miedzinski, L.; Goade, D.; Pavia, A.T.; Hjelle, B.; Hansbarger, C.O.; Levy, H.; Koster, F.T.; Baum, K.; Lindemulder, A.; et al. Placebo-controlled, double-blind trial of intravenous ribavirin for the treatment of hantavirus cardiopulmonary syndrome in North America. Clin. Infect. Dis. 2004, 39, 1307-1313.

44. Chapman, L.E.; Mertz, G.J.; Peters, C.J.; Jolson, H.M.; Khan, A.S.; Ksiazek, T.G.; Koster, F.T.; Baum, K.F.; Rollin, P.E.; Pavia, A.T.; et al. Intravenous ribavirin for hantavirus pulmonary syndrome: Safety and tolerance during 1 year of open-label experience. Ribavirin Study Group. Antivir. Ther. 1999, 4, 211-219.

45. Borio, L.; Inglesby, T.; Peters, C.J.; Schmaljohn, A.L.; Hughes, J.M.; Jahrling, P.B.; Ksiazek, T.; Johnson, K.M.; Meyerhoff, A.; O'Toole, T.; et al. Hemorrhagic fever viruses as biological weapons: Medical and public health management. JAMA 2002, 287, 2391-2405.

46. Fernandez, H.; Banks, G.; Smith, R. Ribavirin: A clinical overview. Eur. J. Epidemiol. 1986, 2, 1-14.

47. Fisher-Hoch, S.P.; Khan, J.A.; Rehman, S.; Mirza, S.; Khurshid, M.; McCormick, J.B. Crimean Congo-haemorrhagic fever treated with oral ribavirin. Lancet 1995, 346, 472-475.

48. Pergam, S.A.; Schmidt, D.W.; Nofchissey, R.A.; Hunt, W.C.; Harford, A.H.; Goade, D.E. Potential renal sequelae in survivors of hantavirus cardiopulmonary syndrome. Am. J. Trop. Med. Hyg. 2009, 80, 279-285.

49. Hooper, J.W.; Kamrud, K.I.; Elgh, F.; Custer, D.; Schmaljohn, C.S. DNA vaccination with hantavirus M segment elicits neutralizing antibodies and protects against seoul virus infection. Virology 1999, 255, 269-278.

50. Snell, N.J. Ribavirin-Current status of a broad spectrum antiviral agent. Expert Opin. Pharmacother. 2001, 2, 1317-1324.

(C) 2013 by the authors; licensee MDPI, Basel, Switzerland. This article is an open access article distributed under the terms and conditions of the Creative Commons Attribution license (http://creativecommons.org/licenses/by/3.0/). 